\title{
Brain systems for assessing facial attractiveness
}

\author{
Joel S. Winston ${ }^{\mathrm{a}, *}$, John O’Doherty ${ }^{\mathrm{a}}$, James M. Kilner ${ }^{\mathrm{a}}$, David I. Perrett ${ }^{\mathrm{b}}$, Raymond J. Dolan ${ }^{\mathrm{a}}$ \\ ${ }^{a}$ Wellcome Department of Imaging Neuroscience, University College London, 12 Queen Square, London WC1N 3BG, UK \\ ${ }^{\mathrm{b}}$ Department of Psychology, University of St. Andrews, UK
}

Accepted 4 May 2006

\begin{abstract}
Attractiveness is a facial attribute that shapes human affiliative behaviours. In a previous study we reported a linear response to facial attractiveness in orbitofrontal cortex (OFC), a region involved in reward processing. There are strong theoretical grounds for the hypothesis that coding stimulus reward value also involves the amygdala. The aim of the present investigation is to address whether the amygdala is also sensitive to reward value in faces, indexed as facial attractiveness. We hypothesized that contrary to the linear effects reported previously in OFC, the amygdala would show a non-linear effect of attractiveness by responding to both high and low attractive faces relative to middle attractive faces. Such a non-linear response would explain previous failures to report an amygdala response to attractiveness. Human subjects underwent fMRI while they were presented with faces that varied in facial attractiveness where the task was either to rate faces for facial attractiveness or for age. Consistent with our hypothesis, right amygdala showed a predicted non-linear response profile with greater responses to highly attractive and unattractive faces compared to middle-ranked faces, independent of task. Distinct patterns of activity were seen across different regions of OFC, with some sectors showing linear effects of attractiveness, others exhibiting a non-linear response profile and still others demonstrating activation only during age judgments. Significant effects were also seen in medial prefrontal and paracingulate cortices, posterior OFC, insula, and superior temporal sulcus during explicit attractiveness judgments. The non-linear response profile of the amygdala is consistent with a role in sensing the value of social stimuli, a function that may also involve specific sectors of the OFC.
\end{abstract}

(C) 2006 Elsevier Ltd. All rights reserved.

Keywords: Amygdala; Orbitofrontal cortex; Reward; Face processing; Social judgment

\section{Introduction}

Human attractiveness conveys significant biological advantages as expressed in mating success (Pashos \& Niemitz, 2003; Thornhill, Gangestad, \& Comer, 1995), earning potential (Frieze, lson, \& Russell, 1991) and longevity (Henderson \& Anglin, 2003). It can be conjectured that facial attractiveness is an important variable in mate choice (Fink \& Penton-Voak, 2002; Thornhill \& Gangestad, 1999) and that evolved brain systems show sensitivity to this aspect of the sensory environment. The idea that the human brain possesses regions responsive to attractiveness is supported by data from brain imaging studies. Aharon et al. (2001) showed that attractive female faces activate reward regions in men more than attractive males or unattractive faces of either gender. O'Doherty et al. (2003) showed dissociable regions of prefrontal cortex responded to attractive and

\footnotetext{
* Corresponding author. Tel.: +44 207833 7477; fax: +44 2078131420

E-mail address: j.winston@ fil.ion.ucl.ac.uk (J.S. Winston).
}

unattractive faces; specifically showing that medial prefrontal regions, including medial orbitofrontal cortex, responded to attractive faces and lateral regions respond more to unattractive faces. The theoretical approach in both these studies was to treat viewing of attractive faces as akin to reward, an approach vindicated by behavioural data showing that men work to observe attractive female faces, but not unattractive females or any male face (Aharon et al., 2001). In addition, behavioural evidence demonstrates that an attractive female face will lead men to discount higher future rewards against smaller immediate rewards (Wilson \& Daly, 2004), consistent with this construal of attractive faces as rewards.

While these previous studies have implicated the orbitofrontal cortex in facial attractiveness, another region thought to have an important role in coding stimulus reward-value as well as in evaluating social stimuli is the amygdala (for a review see e.g. Baxter \& Murray, 2002). However, previous neuroimaging studies of attractiveness have failed to demonstrate activation in this region which we conjecture reflects an assumption that the amygdala responds linearly across "valence space". How- 
ever, evidence that the amygdala may show a response to a broad range of emotions relative to stimuli of neutral valence (Garavan, Pendergrass, Ross, Stein, \& Risinger, 2001; Hamann, Ely, Grafton, \& Kilts, 1999; Winston, O’Doherty, \& Dolan, 2003) predicts non-linear responses to facial attractiveness, responding to both high and low attractiveness stimuli compared to those of average attractiveness. In other words, we predict that the amygdala may respond maximally to stimuli at both extremes of valence.

In previous studies, responses to attractive faces were measured while subjects performed an unrelated task in which subjects did not directly assess stimuli for attractiveness (Aharon et al., 2001; O'Doherty et al., 2003). The fact that robust reward-related responses were found in these studies suggests that neural responses to facial attractiveness are automatically engaged even if subjects are performing an unrelated task. In the present study we aimed to investigate this phenomenon in more detail by exploring the degree to which responses to facial attractiveness were modulated as a function of task. Specifically, we aimed to compare neural responses to facial attractiveness while subjects performed an explicit judgment of facial attractiveness compared to neural responses elicited during performance of an implicit task in involving an relatively unrelated facial judgment (age). We hypothesized that explicit judgments of attractiveness might enhance responses in reward-related regions, in a manner analogous to the effect of attentional modulation on neural responses to other visual stimulus properties such as colour or motion (e.g. Corbetta, Miezin, Dobmeyer, Shulman, \& Petersen, 1991).

To address these questions we used a factorial fMRI experimental design with a parametric factor of attractiveness, and categorical factors of task, stimulus (face) gender and subject gender. Stimulus and subject gender have been shown to be important in processing of facial attractiveness (e.g. Aharon et al., 2001; O'Doherty et al., 2003), and were therefore included as experimental variables. Aside from the amygdala and OFC the key regions of interest in this report are the core components of the distributed system for face perception (Haxby, Hoffman, \& Gobbini, 2000), namely fusiform and superior temporal sulcus (STS).

\section{Methods}

\subsection{Stimuli}

Insufficient stimuli were available in our original set, as our previous aim was to examine effects of extreme attractiveness rather than characterising responses across an "attractiveness space". Consequently, we supplemented the stimuli from O'Doherty et al. (2003b) with additional faces from similar sources. The additional stimuli were picked by the authors primarily to be of average attractiveness. Stimuli, which were colour image files, were cropped similarly to the originals with little hair visible and adjusted to have equal mean luminance. Faces had direct eye-gaze and head direction and were approximately coregistered for eye-position. As in the previous study, images showed expressions between neutral and mild smiles. Seventy-two images were used (36 women).

\subsection{Subjects}

fMRI data was obtained from 28 healthy subjects (13 women) with normal or corrected-to-normal vision who gave informed consent to take part in the study which had been approved by the local ethics committee. Data from two subjects (both males) were excluded after a debriefing questionnaire revealed non-hetrosexual preferences (self-rated sexuality $<5$ on scale where $1=$ exclusively homosexual and $7=$ exclusively heterosexual). The age range of the remaining subjects was $18-35($ mean $=25.5)$, with no significant difference between the ages of males and females $(p=0.12)$.

\subsection{Experimental paradigm}

Subjects performed one of two tasks on the face stimuli, with task alternating in a blocked fashion. In the attractiveness task subjects made a judgment of attractiveness with one of three buttons ("highly attractive", "medium", "low attractiveness"). In the age task subjects judged the age of the face as being young, medium or old, with three buttons to represent the response. Blocks of each task were preceded by an instruction and a summary instruction remained onscreen during each block. Stimuli were presented for $1000 \mathrm{~ms}$ and interstimulus interval (ISI) was $1900 \mathrm{~ms}$. Blocks consisted of nine stimuli giving an overall block length of $26 \mathrm{~s}$. In total, there were 16 blocks for each task and each stimulus was presented twice in the context of each task. The starting block was counterbalanced across-subjects.

\section{4. fMRI data}

Data were collected on a 1.5 T MRI scanner (Siemens, Erlangen, Germany) using gradient echo $\mathrm{T} 2 *$-weighted echo-planar images, with blood oxygenation level dependent (BOLD) contrast. Volumes consisted of 36 slices angled at $-30^{\circ}$ to the horizontal. Tilting of slices in this manner improves image quality in the ventral prefrontal cortex (Deichmann, Gottfried, Hutton, \& Turner, 2003). The effective repetition time (TR) was $3.2 \mathrm{~s}$, and 295 volumes were collected, with the first five subsequently discarded. Slice thickness was $2 \mathrm{~mm}$ with a $1 \mathrm{~mm}$ gap between slices and in-plane resolution was $3 \mathrm{~mm} \times 3 \mathrm{~mm}$. The use of low field strength MRI, tilted axial acquisition, thin slice thickness, and fine in-plane resolution all aid signal quality in amygdala (Chen, Dickey, Yoo, Guttmann, \& Panych, 2003; Robinson, Windischberger, Rauscher, \& Moser, 2004). A T1weighted structural image was acquired for each subject for detailed anatomical information.

\subsection{Debriefing}

Participants undertook two debriefing tasks outside the scanner. They first rated all the faces on attractiveness, using a computerised visual analogue scale. The scale was marked with extremes as "highly unattractive" and "highly attractive", with the mid-point marked; participants could leave the cursor at any point in between the two extremes. Ratings were scaled between -10 and +10 with +10 representing ratings of high attractiveness, though numbers were not apparent to the participant. Subsequently they rated the faces on happiness on a similar scale with the extremes labelled "happy" and "unhappy", and the mid-point indicated. Participants also provided information concerning their sexual orientation on an ordinal scale.

\subsection{Data analysis}

Imaging data were pre-processed and analysed using SPM2 (Wellcome Department of Imaging Neuroscience, London; http://www.fil.ion. ucl.ac.uk/spm). Preprocessing consisted of determining and applying rigid affine transformations to the image series to realign the scans (Friston et al., 1995a), slice timing correction (Henson, Buchel, Josephs, \& Friston, 1999), normalisation (Friston et al., 1995a) to a standard EPI template in MNI space and smoothing with a three-dimensional $8 \mathrm{~mm}$ Gaussian kernel to account for residual inter-subject anatomical differences.

Because the factor of task was blocked, but the order, gender and perceived attractiveness of face stimuli were randomised, the experimental design conforms to a mixed block/event-related paradigm. Task was blocked in order to minimise the number of task switches required of subjects. However, in an experimental design such as the one adopted here, with parametric interpretation of events based upon post hoc ratings, it is impossible to block the stimulus type 
(Josephs \& Henson, 1999). Such mixed designs have specific advantages that have been outlined by Donaldson (2004).

Data were analysed statistically using a two-stage procedure. Event onsets were modelled by delta functions which were subsequently convolved with a synthetic haemodynamic response function (HRF; Friston et al., 1998). In addition to the delta functions of unit height corresponding to the onset of each face within each of the four conditions (male face, age task; female face, age task; male face, attractiveness task; female face, attractiveness task), six additional delta functions convolved with an HRF were used for each condition. Four of these were parametrically modulated by a series of polynomial expansions of the subject-specific rating of attractiveness for each face (see Buchel, Holmes, Rees, \& Friston, 1998a). This high order expansion gives confidence in attributing response profiles-if a smaller expansion were used, underlying relationships that were in fact exponential could be misinterpreted as quadratic for example. A fifth set of delta functions was modulated by the subject-specific rating of happiness for the faces and a sixth set by the interaction of happiness and attractiveness ratings (the dot product of the mean-corrected parameters). The design matrix consisted of these 28 regressors along with seven regressors of no interest and a constant term. The regressors of no interest comprised one regressor pertaining to the reaction time for each trial and six movement parameters. Effect sizes were estimated for each regressor in the design matrix within the framework of the generalised linear model (Friston et al., 1995b) and contrasts pertaining to the main effects and interactions of the factorial design were calculated for each subject. In the second stage of analysis the consistency of these effects across the population of subjects was tested (random effects analysis).

In all models reported (with the exception of conjunction models), males and females were treated as separate groups in an ANOVA model and equal variance was not assumed using SPM2's options for non-sphericity correction (Glaser $\&$ Friston, 2003). For conjunctions, men and women were treated as a single group and non-sphericity correction was applied for the non-independence of the contrasts of parameter estimates from this repeated measure design. $p<0.05$ corrected for multiple comparisons across the brain using Gaussian random field theory (Worsley et al., 1996) was considered the threshold for statistical significance. Exceptions were made in a priori regions of interest, where we used the more liberal threshold of $p<0.001$ uncorrected and indicate if the activation survived a correction for multiple comparisons over a small region of interest (Worsley et al., 1996). Regions of interest were medial and lateral orbitofrontal cortex, medial prefrontal cortex and anterior insula, based upon our previous study (O'Doherty et al., 2003). In addition regions considered to comprise the core system for human face perception (Haxby et al., 2000), namely fusiform cortex and superior temporal sulcus were considered a priori regions of interest. Finally, the amygdala was a prime region of interest, given our prediction of non-linear responses in this region. Medial OFC and inferior medial PFC were mapped using the mean anatomical images and delineated to include gyrus rectus, frontomarginal gyrus and medial orbital gyrus inferiorly and supraorbital gyrus medially and superiorly, with a total mask volume of $20 \mathrm{~cm}^{3}$. The amygdala was delineated bilaterally on the mean anatomical images, and the total mask volume was $8 \mathrm{~cm}^{3}$. Fusiform and STS were delineated using an activation mask from a previous study on an independent subject cohort (Winston, Henson, Fine-Goulden, \& Dolan, 2004).

Given the importance of the results in the amygdala in this study, an additional region of interest (ROI) analysis was carried out on data from this region. Using anatomical masks of left and right amygdala, parameter estimates for effects of interest were collected and averaged for each subject. These average effects were then entered into $t$-tests checking for hemisphere-by-condition interactions in amygdala and for simple effects within each hemisphere.

\subsection{Behavioural data during scanning}

Ratings of attractiveness during the attractiveness task (for comparison to debriefing ratings) and response times for both conditions were obtained in every subject except one male owing to technical failure. Responses faster than $200 \mathrm{~ms}$ or slower than 2 standard deviations above the within-subject mean were excluded as outliers from further analysis (mean proportion of excluded data $=3.5 \%$, range $=1.7-5.7 \%$ ). Unfortunately, owing to technical failure, pupillometric data were not available in all subjects. Such data were obtained in 16 of the subjects ( 6 women). Eyeblinks were removed by interpolation between points where pupil diameter was below $80 \%$ of the mean signal (excluding zeros) across the epoch. These behavioural data were analysed in a two-stage model similar to the fMRI analysis. Thus, in a first stage procedure the data were modelled with parametric polynomial expansions pertaining to attractiveness and linear trends for happiness and the interaction between happiness and attractiveness. A second stage examined for consistency in these effects across-subjects using ANOVAs. Three measures of pupil data were taken, namely the mean, minimum and maximum of response during a $2033 \mathrm{~ms}$ window after presentation of the face stimulus. In addition, trial-by-trial measures of response times (and pupillometry in supplementary analyses) were used as parametric covariates of no interest in fMRI data analysis to ensure BOLD effects were not a result of behavioural "confounds".

\section{Results}

\subsection{Behavioural data}

Ratings of attractiveness during the scanning session correlated well with ratings from debriefing in 24 subjects (out of 25 for whom data were available from the scanning session). Across the group the mean slope of this regression was posi-
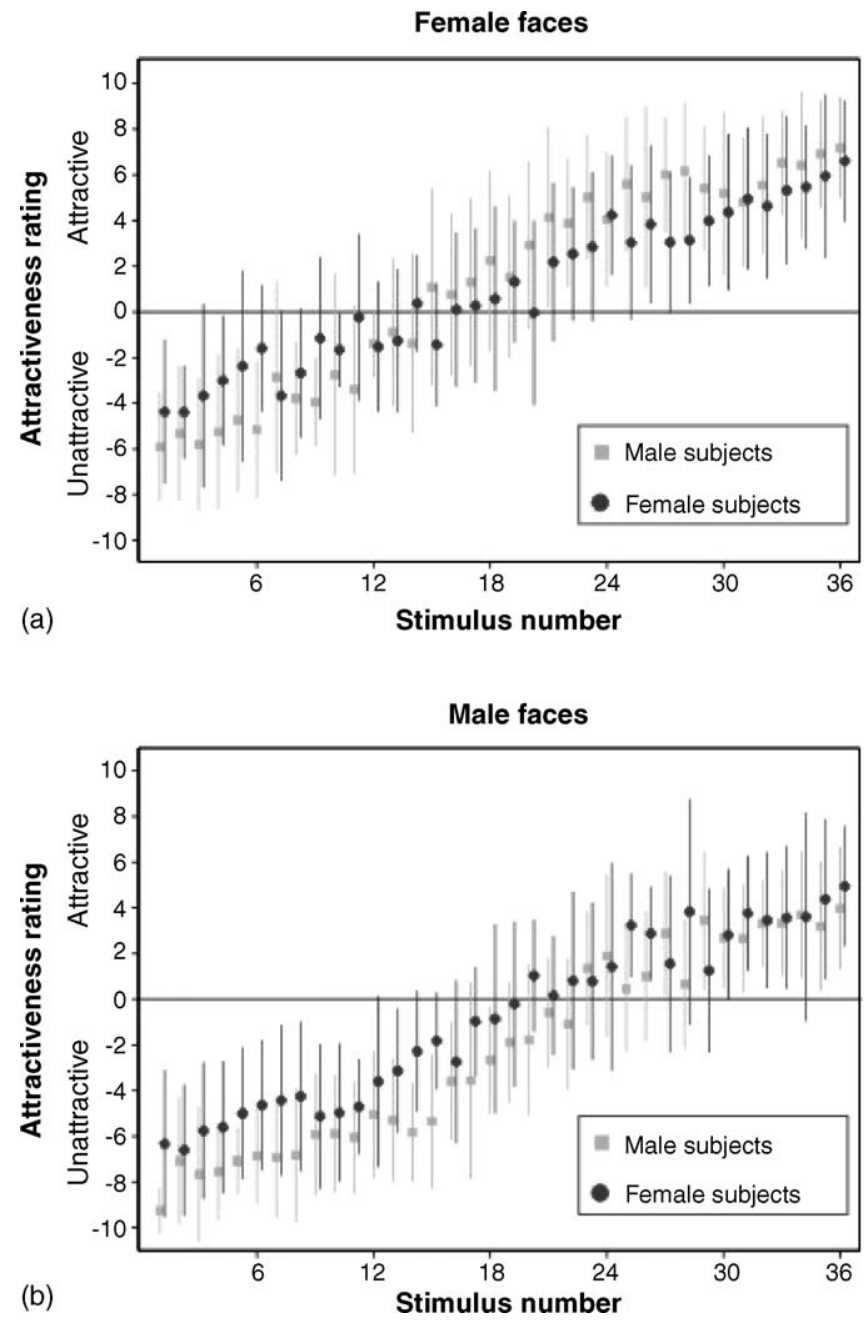

Fig. 1. Behavioural ratings of facial attractiveness. Faces spanned a range of attractiveness ratings for both male and female subjects. Here, stimuli are rankordered by mean score across-subject gender for female (a) and male (b) faces, and mean ratings for male and female subjects are given separately. There was good inter-subject and inter-gender agreement. Error bars are standard deviation. 
tive and significantly different from zero $\left(t_{24}=17.0, p<0.001\right)$ indicating strong within-subject agreement for ratings obtained inside and outside the scanner.

The stimuli represented a broad range of attractiveness (Fig. 1). Two measures suggest that ratings of attractiveness and happiness were significantly (positively) correlated across the group of subjects. First, there was a marginally significant correlation between the mean ratings of happiness and attractiveness across the 72 stimuli $\left(p=0.050 ; r^{2}=0.05\right)$. Second, the across-subjects average slope of within-subject regression of happiness on attractiveness ratings was significantly above zero $\left(t_{25}=6.05 ; p<0.001\right)$. There was no significant difference between men and women with regard to the magnitude of this correlation $(p=0.80)$. This correlation between attractiveness and happiness rendered this experiment relatively insensitive to the interaction between perceived smile and attractiveness previously described (O'Doherty et al., 2003). Since our primary interest was attractiveness, happiness ratings entered into the design matrix for fMRI data were orthogonalised with respect to attractiveness.

Analysis of response time (RT) data during the fMRI experiment revealed a highly significant main effect of task $\left(F_{1,23}=43.16 ; p<0.001\right)$ and a significant task by stimulus (face) gender interaction $\left(F_{1,23}=7.05 ; p=0.014\right)$, driven by faster responses in the attractiveness task (mean RT in attractiveness task $=1043 \mathrm{~ms}$; mean RT in age task $=1139 \mathrm{~ms}$ ) with a significant difference between female and male faces in the attractiveness task alone (mean difference between male and female faces in age task $=16 \mathrm{~ms} ; t_{24}=1.50 ; p=0.15$; female faces associated with faster responses; mean difference between male and female faces in attractiveness task $=44 \mathrm{~ms} ; t_{24}=6.49$; $p<0.001$; female faces associated with slower responses). Given that RTs were modelled in our analysis of fMRI data, we can rule out linear effects of this confounding variable explaining imaging results reported below.

We were concerned that age judgments might be related to attractiveness judgments given previous behavioural evidence for a relationship between youthfulness and beauty (Ishi, Jiro, Kamachi, Mukaida, \& Akamatsu, 2004). To investigate this we undertook regression analysis between age scores from the scanning session and post-scanning attractiveness scores. No significant relationship was found using across-subject average scores for each stimulus $\left(F_{71}=0.77 ; p=0.38 ; r^{2}=0.01\right)$ or a second level approach, testing for consistency of within-subject effects $\left(t_{24}=1.21 ; p=0.24\right)$. An additional analysis was undertaken to explore possible relationships between task difficulty and perceived age. RTs in either task were regressed against perceived age within-subject and parameter estimates for the slope of regression entered into a one-sample $t$-test. No significant effect was found across subjects (attractiveness judgments: $t_{24}=-1.41 ; p=0.17$; age judgments: $t_{24}=-0.90 ; p=0.38$ ).

No significant main effect was seen in analysis of pupillometry data, indicating that there was no overall simple (first or second order) relationship between pupil dilation and attrac- (a) (i)

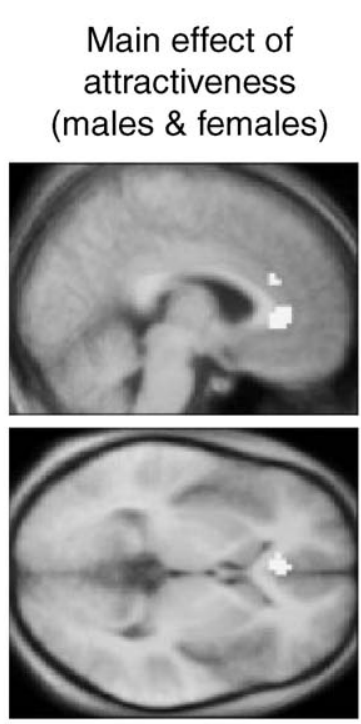

(ii)

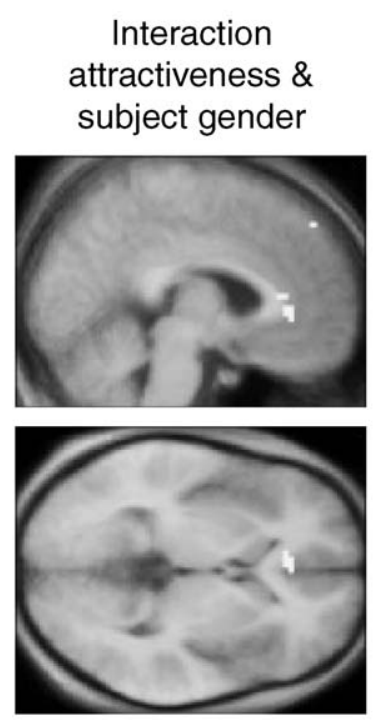

(b)
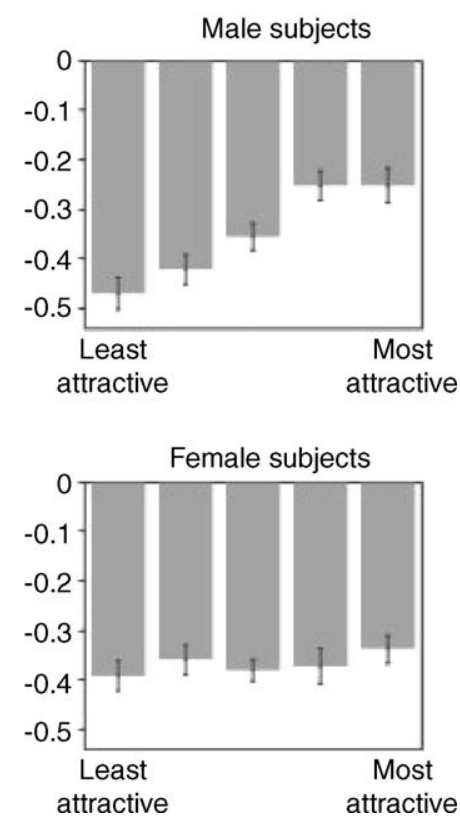

Fig. 2. Anterior cingulate shows a subject gender-by-attractiveness interaction. (a) (i) Although anterior cingulate shows a significant main effect of attractiveness, this is clarified by an attractiveness-by-subject gender interaction (ii). (i) and (ii) are statistical parametric maps (SPMs) of the main effect of attractiveness (attractive > unattractive; activation shown as white) and interaction between attractiveness and subject gender, respectively. SPMs are overlaid on mean T1-weighted image from the 26 subjects; $p<0.001$ uncorrected is used as the threshold for display. (b) Only men show a clear pattern of responding more to attractive than unattractive faces. Data are derived from a subsidiary model in which stimuli were divided into five equally-sized groups for each subject based upon attractiveness scores and fMRI data fitted to this model. Parameter estimates of size of response are averaged for each cohort of faces. Note that there was no baseline condition nor any null event in the experimental design so responses can be interpreted only with respect to one another, not with respect to zero. (Units are \% signal change, error bars are standard error of the mean.). 
tiveness rating. Interestingly, however, there were interactions between attractiveness and subject gender for two of the three measures of pupil response tested (mean $[p=0.02]$ and maximum $[p=0.007])$. In both cases the interaction was driven by a significant correlation between attractiveness rating and pupil response in the male subjects that was not present in women (mean: men one-sample $t$-test, $t_{9}=-3.45, p=0.007$; women one-sample $t$-test, $t_{5}=0.92, p=0.40$; maximum: men one-sample $t$-test, $t_{9}=-5.29, p<0.001$; women one-sample $t$ test, $t_{5}=1.03, p=0.35$ ). This indicates that men showed arousal profiles linearly sensitive to the dimension of attractiveness (showing greater pupil dilation for less attractive faces) whereas women did not.

\section{2. fMRI data}

\subsubsection{Main effect of attractiveness}

A significant positive effect of attractiveness (greater attractiveness associated with linear increases in BOLD) was seen in anterior cingulate (Fig. 2a). However, this main effect was driven primarily by a subject gender-by-attractiveness interaction, as the effect of enhanced cingulate response to attractive faces was expressed solely in men (Fig. $2 \mathrm{~b} ; x, y, z=-3,36,0 ; Z$ for interaction $=3.71 ; p<0.001$ uncorrected two-tailed). Left mid-insula showed positive linear effects of attractiveness that bordered significance ( $x, y, z=-42,0,15 ; Z=4.71 ; p=0.063$ corrected). Enhanced activations to attractiveness in a priori regions of interest included left posterior occipito-temporal cortex extending into lateral fusiform $(x, y, z=-48,-66,-15 ; Z=4.27 ; p<0.001$ uncorrected; fusiform peak: $x, y, z=-39,-69,-12 ; Z=3.92$; $p<0.001$ uncorrected), and orbitofrontal cortex $(x, y, z=-21$, 54, $-9 ; Z=3.97 ; p<0.05$ small volume corrected (SVC); $x, y$, $z=-15,48,-15 ; Z=3.11 ; p<0.001$ uncorrected; Fig. 3). The peak in left occipito-temporal cortex and fusiform did not overlap with a mask outlining face-responsive regions used for SVC (see methods), so was not explored further. The OFC region showed significant effects in men and women and across tasks, as evidenced by conjunction analyses.

No region showed significant effects for the linear effect of unattractiveness.

\subsubsection{Main effect of task}

Significant main effects of task were seen in a number of regions (Table 1) including bilateral superior temporal sulcus (STS) (attractiveness task > age task) along the A-P axis (Fig. 4). A large region of superior medial prefrontal/paracingulate cortex showed a similar effect as did bilateral posterior orbitofrontal cortex (OFC)/anterior insula (Fig. 5). The activation of left pos- (a)

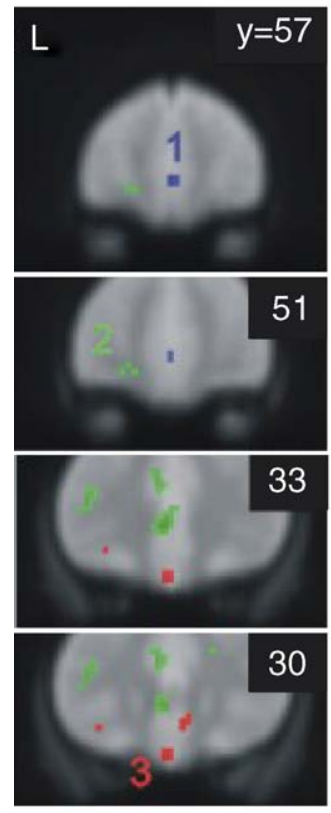

(b)

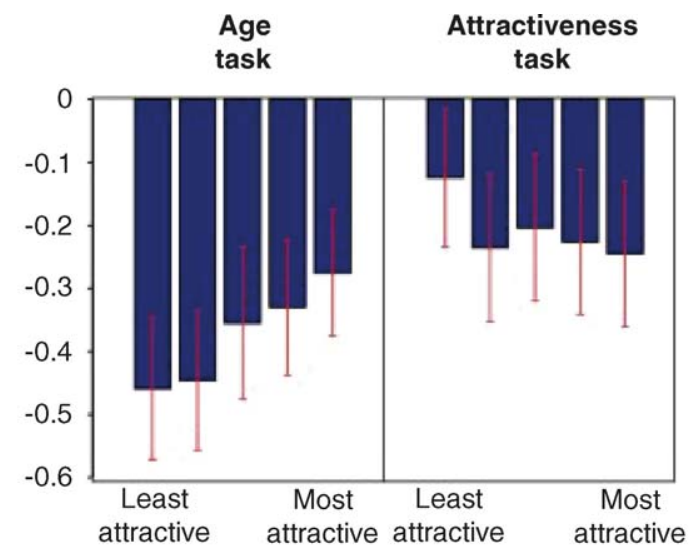

(ii)

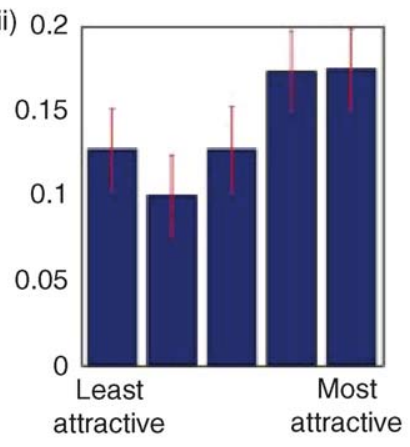

(iii)

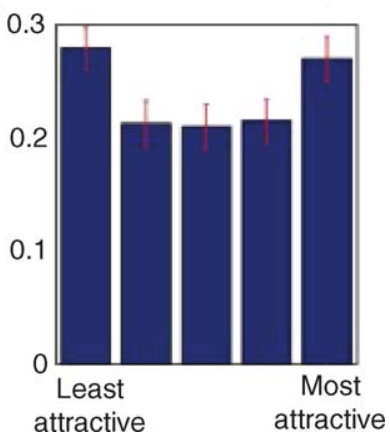

Fig. 3. OMPFC shows segregated responses to attractiveness. (a) Three different SPMs overlaid on mean echoplanar image. Blue shows interaction between task and attractiveness. Red shows regions with significant positive second order effects of attractiveness. Green shows main effect of attractiveness (attractive $>$ unattractive). All thresholded at $p<0.001$ uncorrected. Peaks discussed in text and illustrated further in part (b) are labelled 1-3. (b) Illustration of effects shown in (a): (i) Inferior medial prefrontal cortex shows an interaction between task and attractiveness, with a linear positive increase in activation with increasing attractiveness under the age task but a decreasing response with increasing attractiveness under the attractiveness judgment task. Data derived as in Fig. 2b. (ii) A portion of medial OFC shows a main effect of attractiveness with greater responses to attractive than unattractive faces. (iii) Posterior medial OFC shows significant non-linearity in response to attractiveness with extremes of attractiveness generating greater activation than faces of medium attractiveness. (For interpretation of the references to colour in this figure legend, the reader is referred to the web version of the article.) 
Table 1

Brain regions showing significant differences in BOLD activation in a task-dependent manner (attractiveness judgment $>$ age judgment; all $p<0.05$ corrected for whole brain volume, extent threshold of five voxels)

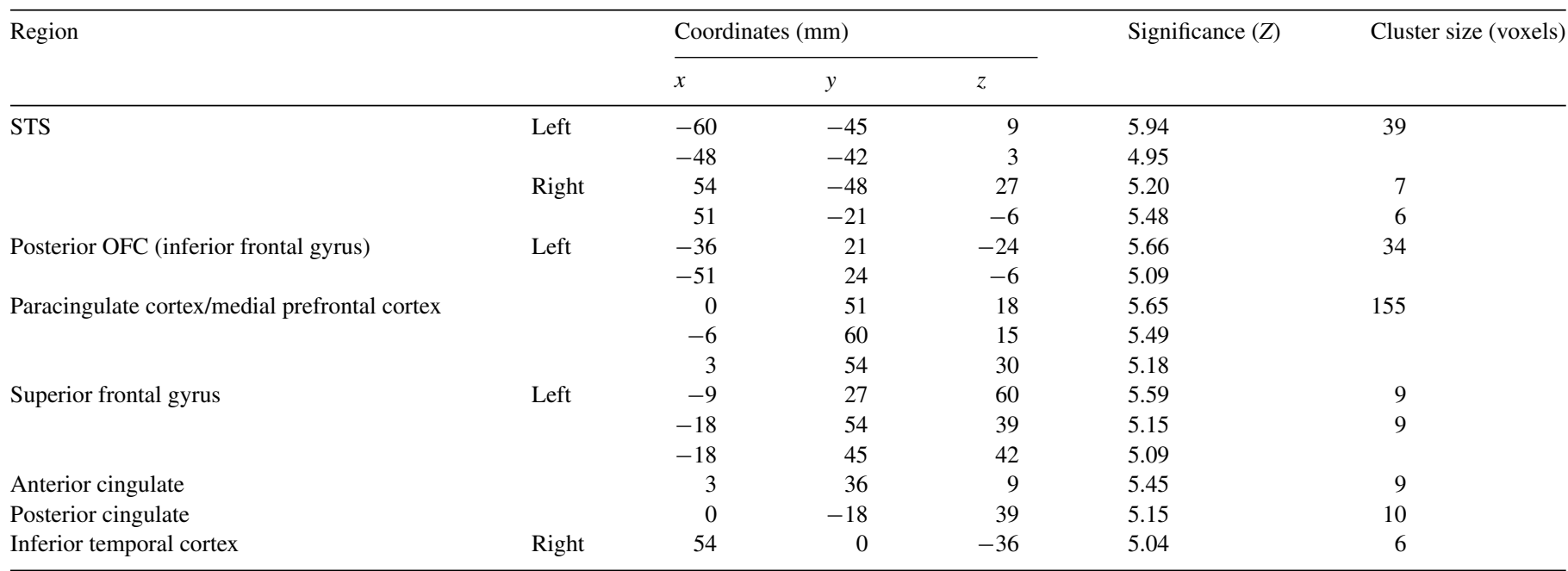

terior OFC/insula extended posteriorly (at uncorrected thresholds) into amygdala (peak at $x, y, z=-24,0,-24 ; Z=4.11$; $p<0.001$ uncorrected). A subsidiary ROI analysis on amygdala data confirmed this main effect of task in left amygdala $(Z=2.33$,

(a)
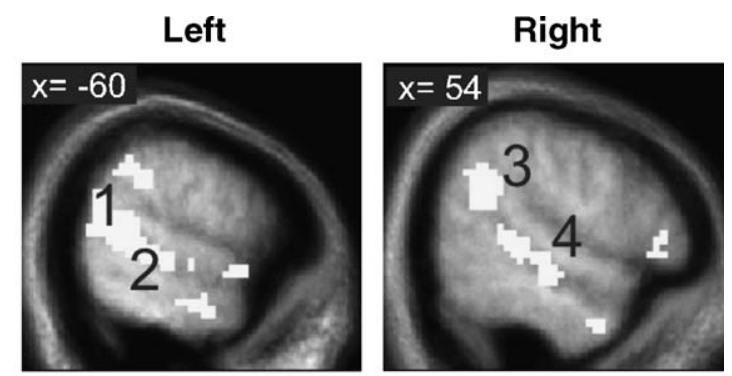

(b)

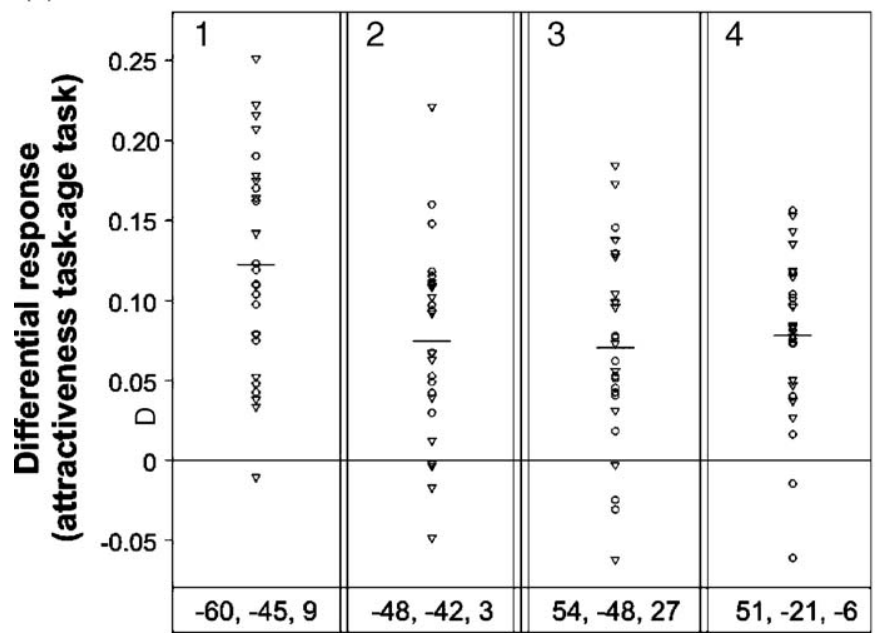

Fig. 4. STS shows enhanced responses during attractiveness judgments. (a) SPM showing main effects of task (attractiveness judgment $>$ age judgment). Display as in Fig. 2a. Four peaks within STS (labelled 1-4) show significant effects corrected for multiple comparisons across the whole brain. (b) Differential effects for each peak are shown in the plots: triangles represent men and circles women. The horizontal line shows mean differential response between the two tasks. (Units are \% signal change.). $p<0.05$; two-tailed $t$-test) and indicated that no similar effect was present in right amygdala $(Z=0.70, p=0.48)$. Moreover, there was a significant difference in response profile between left and right amygdala with regard to the main effect of task, as indicated by a significant hemisphere-by-condition interaction $(Z=2.61, p<0.01)$.

In the opposite contrast, significant effects resulting from greater responses during the age task were seen in right posterior (retrosplenial) cingulate cortex $(x, y, z=12,-51,18 ; Z=5.84$; $p<0.05$ corrected) alone. At uncorrected thresholds a similar region was also seen on the left $(x, y, z=-9,-54,12 ; Z=4.45$; $p<0.001$ uncorrected).

\subsubsection{Task by attractiveness interaction}

Inferior medial prefrontal cortex close to the region shown to respond to attractiveness during gender judgments by (O'Doherty et al., 2003) showed an interaction between task and attractiveness $(x, y, z=0,60,-6 ; Z=3.68 ; p<0.001$ uncorrected; Fig. 3). This interaction took a cross-over form, with positive relationship between attractiveness and activation during the age judgment task ( $p<0.001$, two-tailed $t$-test) and a negative correlation under the attractiveness judgment task $(p<0.028$, two-tailed $t$-test).

\subsubsection{Non-linear effects of attractiveness}

Significant positive second order relationships between BOLD activation and attractiveness score were seen in right amygdala ( $x, y, z=27,0,-24 ; Z=3.52 ; p<0.05$ SVC; Fig. 6), right middle temporal gyrus adjacent to the lower bank of the STS $(x, y, z=60,-42,0 ; Z=4.39 ; p<0.001$ uncorrected), and medial OFC $(x, y, z=-3,30,-27 ; Z=3.60 ; p<0.001$ uncorrected; Fig. 3). These regions showed greater activation when subjects observed highly attractive or unattractive faces than faces of medium attractiveness. All of these activations were task-independent, as evidenced by significant results in a conjunction analysis across the factor of task. The response in right amygdala was independent of subject gender or face gen- 
(a)
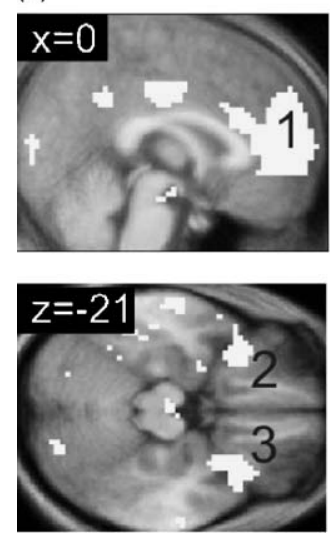
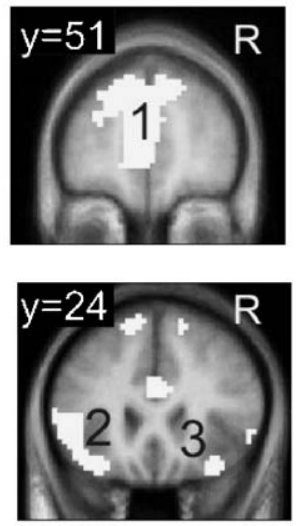

(b)

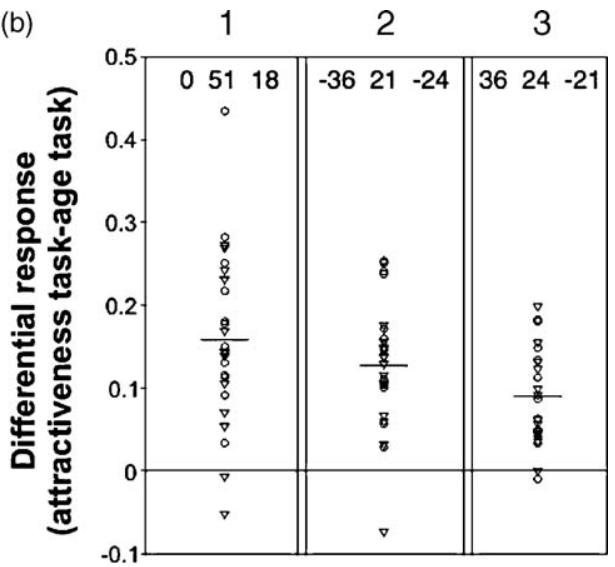

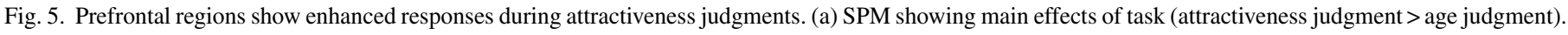

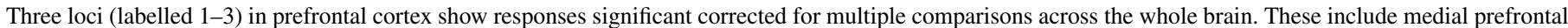

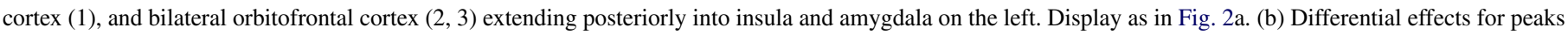
1-3. Triangles represent men and circles women. The horizontal line shows mean differential response between the two tasks.

der, as shown by conjunction analyses across these factors $(x, y$, $z=27,0,-21 ; Z=3.91 ; p<0.05$ SVC; Fig. 6). Visible in Fig. 6 is a trend to unattractive faces yielding greater activation than attractive faces, consistent with a marginal negative regression slope for the linear term at the peak voxel from the non-linear effect $(Z=1.80, p<0.05$ uncorrected). Interestingly, the nonlinearity appears less prominent in men observing male faces (Fig. 6), though this effect did not reach statistical significance. For the 16 subjects for whom arousal (pupillometric) data were available, inclusion of this data into the statistical model as a covariate of no interest made no discernable difference to the results in the amygdala $(x, y, z=27,0,-24 ; Z=3.64 ; p<0.05$ SVC).
Although in the SPM data analysis effects were only seen in right amygdala at a priori thresholds, when inspected at reduced thresholds similar non-linear effects were apparent in left amygdala (e.g. $x, y, z=-15,-9,-27 ; Z=2.69$; $p<0.005$ uncorrected; $x, y, z=-21,-3,-33 ; Z=1.74$; $p<0.05$ uncorrected). This suggests that the non-linear relationship between perceived attractiveness and BOLD activation in amygdala is not limited to the right hemisphere. Moreover, when formally tested by means of a subsidiary ROI analysis explicitly comparing right and left amygdala, a significant second-order effect was detectable in both hemispheres (left: $Z=2.51, p<0.05$; right: $Z=2.21, p=0.051$; two-tailed $t$-tests) and no hemispheric difference in degree (a)

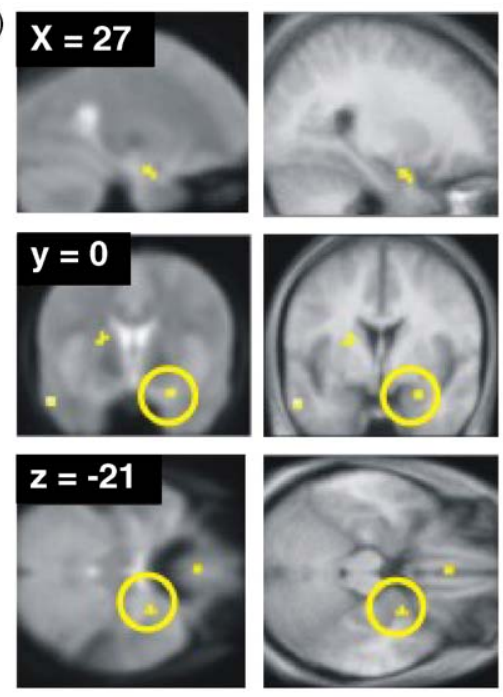

(b) Female subjects viewing male faces

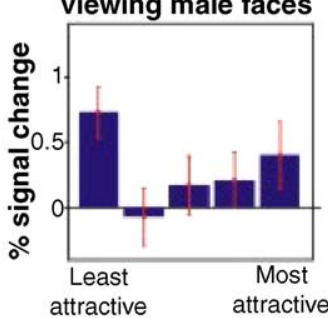

Male subjects viewing male faces

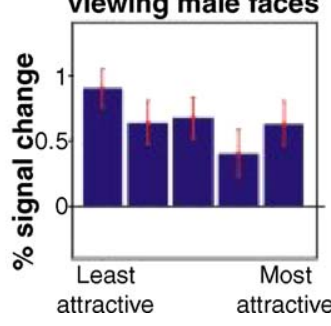

Female subjects viewing female faces

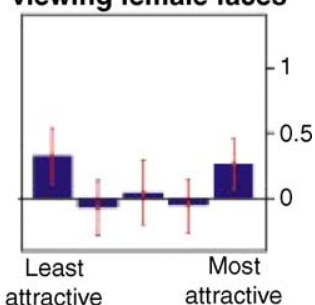

Male subjects viewing female faces

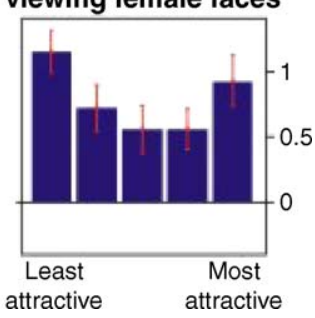

Fig. 6. Amygdala shows non-linear responses across attractiveness space. (a) Sagittal (top), coronal (middle) and axial (bottom) sections through group average scans with overlaid SPM of quadratic relationship between attractiveness score and BOLD activity. The statistical image is overlaid on the mean normalised EPI (left) and mean structural image (right) of the subject cohort. Activation is seen in anterior lateral right amygdala $(x, y, z=27,0,-21 ; Z=3.59 ; p<0.05$ small volume corrected). SPM thresholded at $p<0.001$ uncorrected. (b) Responses in right amygdala were non-linear, independent of subject and face gender. Women (top row) show a non-linear relationship between activation and attractiveness when looking at male (left) or female (right) faces, as do men (bottom row). Data from conjunction peak at $x, y, z=27,0,-21(Z=3.91, p<0.05$ SVC $)$, derived as in Fig. 2 b. 
of nonlinearity was detected $(Z=0.55, p=0.58$; two-tailed $t$-test).

\section{Discussion}

In this study, we explored brain responses to faces which varied in attractiveness and additionally task effects on those responses. By using a set of faces that varied on attractiveness we characterised both linear and non-linear relationships between attractiveness and brain response. The inclusion of a task that directly asked subjects to rate attractiveness along with a task that was relatively unrelated (age judgment) allowed us to investigate the degree to which activations were task-dependent or independent.

Our stimulus set contained faces of a limited age range. This was deliberately adopted so as to make age judgments a reasonably demanding control task, and additionally so that age might be less confounded with attractiveness than it is when a larger age range is considered or when age is directly manipulated in a controlled manner by the experimenter (see e.g. Deffenbacher, Vetter, Johanson, \& O'Toole, 1998; Ishi et al., 2004). This strategy was successful, given the absence of correlation between perceived age and attractiveness and the lack of significant RT effects associated with the factor of age in either task. Broader behavioural studies would be important for establishing to what extent these negative findings are specific to our stimuli.

The two primary questions addressed in this study (effects of task in reward paradigms and of non-linear stimulus-response profiles) have not been widely studied in humans. One early PET study has investigated the effect of judging attractiveness versus judging facial emotion, finding increased $\mathrm{rCBF}$ in left medial frontal cortex and left fronto-temporal junction when subjects made attractiveness judgments (Nakamura et al., 1998). One limitation of this study was not fully optimising the range of attractiveness of the stimuli or separating attractive and unattractive stimuli into separate blocks to test for an interaction between attractiveness and task.

\subsection{Responses associated with attractiveness}

Previous studies have suggested that areas of the brain that respond to other types of reward, such as monetary reward or pleasant chemosensory stimuli also respond more when observing attractive, relative to unattractive, faces (Aharon et al., 2001; O'Doherty et al., 2003). These regions included medial orbitofrontal cortex and the nucleus accumbens in ventral striatum. The latter effect observed by Aharon et al. (2001) in the context of a block-design study was not replicated by O'Doherty et al. (2003), who used a random stimulus order. O'Doherty et al. (2003) suggested that this discrepancy might be explained by a confound of reward anticipation in the block design. Despite the large number of subjects in both O'Doherty et al. (2003) and the current study, we again failed to replicate activation in ventral striatum in response to attractive faces.

In the current study, we hypothesized that the direct attractiveness judgment task would be associated with enhanced acti- vations in regions responsive to attractiveness, given that visual features pertaining to facial attractiveness would be attended to more in the direct task than the unrelated judgment task. Counter to our expectation, sectors of medial OFC responded independent of task, showing similar magnitude of activation in both the direct and indirect task. Moreover, additional regions of medial OFC and medial PFC actually showed the opposite effect, demonstrating enhanced activity to facial attractiveness in the indirect compared to the direct task. These results suggest that neural responses to facial attractiveness are automatically engaged, and that unlike responses to other visual features like colour or motion, neural responses to facial attractiveness are not enhanced as a function of attending to the relevant features (e.g. Buchel et al., 1998b; Corbetta et al., 1991). Indeed it appears that actually attending to facial attractiveness appears to diminish activity in at least some reward-related areas. One possible interpretation of these results is that the reward value (or perhaps aesthetic value) of a visual stimulus is diminished when trying to evaluate it. Clearly further behavioural and neuroimaging research is needed to elucidate this seemingly paradoxical effect.

A finding from our previous study (O'Doherty et al., 2003) of greater activation to unattractive relative to attractive faces in lateral OFC and prefrontal cortex was not replicated in the current experiment. Such null results are hard to interpret. However, one possible explanation is a potential task difficulty confound in O'Doherty et al. (2003) where the task used was gender judgment. This may have been more difficult to perform on the unattractive faces given that one determinant of high facial attractiveness is sexually diamorphic facial features (Perrett et al., 1998). Notably, such an effect of facial attractiveness on gender classification speed (with faster classification for more attractive faces) has previously been reported (O'Toole et al., 1998).

As in our previous study, relatively few regions showed effects dependent upon subject gender. However, one region which did was anterior cingulate cortex. Although this region showed a significant main effect of attractiveness (averaged across both subject genders) this effect was driven entirely by the male subjects as evidenced by a significant attractiveness-by-subject gender interaction (Fig. 2). Interestingly, we found psychophysiological evidence consistent with such an effect in the pupillometry data available from a subset of subjects, which showed a similar attractivenessby-subject gender interaction with effects of attractiveness on pupil dilation expressed only in men. The role of anterior cingulate cortex in generating and monitoring internal autonomic states is well-characterised (Critchley, 2004; Critchley, Elliott, Mathias, \& Dolan, 2000b; Teves, Videen, Cryer, \& Powers, 2004), and these new data suggest that there are between-gender differences in arousal generated to attractive faces.

\subsection{Non-linear response profiles}

As predicted, amygdala showed a significant non-linear response profile, with greatest responses to attractive and 
unattractive faces, relative to those of medium attractiveness. These data extend our understanding of the role of the amygdala in social and emotional perception. Although earlier results have suggested that amygdala is not simply specialised to detect negatively valenced stimuli or a specific type of emotion (e.g. Hamann, Ely, Hoffman, \& Kilts, 2002; Singer, Kiebel, Winston, Dolan, \& Frith, 2004; Winston et al., 2003), to our knowledge there has been no previous description of a non-linear response profile. The demonstration of a non-linear response mode of this type is in keeping with the idea that the amygdala is tuned to the detection of events of emotional value, irrespective of valence, in the sensory environment (Dolan, 2002; Sander, Grafman, \& Zalla, 2003). Recently, it has been suggested that amygdala responses are driven by stimulus intensity (a surrogate for "arousal") rather than valence (Anderson et al., 2003; Small et al., 2003), though these studies adopted chemosensory stimuli and it remains possible that the amygdala is differently engaged by different sensory domains. Additionally, neither study supporting this claim included stimuli with valence close to zero, so it is hard to infer from these data that the amygdala is not representing aspects of valence. Moreover, in the current study, we are able to dissociate activity in the amygdala from at least one direct measure of arousal, pupil dilation. The inclusion of three aspects of pupillary responses as covariates of no interest in the statistical model in 16 subjects for whom these data were available had little effect on the statistical test for non-linearity, indicating that the quadratic relationship between attractiveness rating and amygdala activation was not explained simply by greater arousal at extremes of attractiveness.

Our finding of a portion of medial OFC with significantly non-linear responses to attractiveness, responding more to extremes than to faces of average attractiveness, is a strong demonstration of the utility of the approach adopted in the current study. Previous work (O'Doherty et al., 2003) has shown a simple main effect of attractiveness in this region, and we note that even within this peak voxel in the current study, responses trended towards greater magnitude for attractive than unattractive faces. By using non-linear parametric expansions of our variable of interest in the current study, we are able to make stronger inferences about the underlying relationship than previous studies. Where linear associations are significant we can be more confident that they reflect linear relationships than in previous studies using parametric designs where higher order relationships were not modelled (e.g. Winston, Strange, O’Doherty, \& Dolan, 2002; see also Buchel et al., 1998a; O'Doherty et al., 2003). In addition, this form of response to more and less positive stimuli relative to "average" is not unprecedented in this region: Elliott, Newman, Longe, and Deakin (2003) demonstrated a similar second order relationship between monetary reward and BOLD activation in medial OFC. In that study, only five discrete levels of reward were used, compared to 72 different male and female faces in the current study. This broader range of stimuli reflects a smoother representation of underlying reward value, allowing a fuller characterisation of response profile here.

\subsection{Differential responses as a function of task}

A number of regions were more activated when judging attractiveness compared to age, including bilateral STS, bilateral posterior OFC extending into insula and medial prefrontal cortex. Most striking was the activation of STS and medial prefrontal cortex, as these regions have both been implicated in higher-order social judgments, such as theory-of-mind (see Frith \& Frith, 1999, for a review). Previous studies comparing direct emotional judgments of faces and baseline tasks involving less emotive judgments have also demonstrated activation in these areas (Narumoto, Okada, Sadato, Fukui, \& Yonekura, 2001; Turk et al., 2004; Winston et al., 2003; Winston et al., 2002). One possible explanation for these findings is that these areas are involved in representation of specific aspects of faces and are thus engaged when judgments of such characteristics are made. With the exception of direct judgments of emotion, where it is known that STS contains units encoding specific facial expressions (Hasselmo, Rolls, \& Baylis, 1989; Winston et al., 2004), this explanation seems unlikely to account for these findings. The range of emotional judgments covered in these studies (facial expressions of emotion, trustworthiness and attractiveness) is more consistent with the idea that these regions engage in such judgments in a more domain-general manner. We speculate that this domain-general mechanism may be intention-detection, or theory-of-mind judgment given the strong evidence associating medial prefrontal cortex and STS with such functions (Frith \& Frith, 1999).

The activation of STS is of interest in that it has repeatedly been implicated in studies involving social evaluation. For example this region has been shown to respond to biological motion (Bonda, Petrides, Ostry, \& Evans, 1996; Puce, Allison, Bentin, Gore, \& McCarthy, 1998), face perception (Haxby et al., 2000), judgments of facial emotion (Narumoto et al., 2001; Winston et al., 2003) and trustworthiness (Winston et al., 2002), theory-ofmind or attribution of intentions (Brunet, Sarfati, Hardy-Bayle, \& Decety, 2000; Castelli, Happe, Frith, \& Frith, 2000). The proposed role of some sectors of STS as an "intentionality detector" (Frith \& Frith, 1999) ties these disparate functions together. We would suggest that judging attractiveness engenders such a process in that an integral component of assessing the attractiveness of a conspecific involves an invocation of another's intentions toward oneself, though we cannot rule out other possible explanations for STS activation while making attractiveness judgments. One possibility is that attractiveness and age judgments result from the use of different sorts of information from the face and that STS is involved in the representation of those aspects that are important for attractiveness judgments. The coactivation of other areas such as medial prefrontal cortex that have previously been implicated in social cognition but not in representation of specific facial attributes is perhaps more consistent with an intentionality-detection explanation.

In addition to STS, another region engaged by the attractiveness judgment task and previously implicated in social cognition was medial prefrontal cortex. We note that medial prefrontal cortex has also been implicated in a study comparing evaluative judgments (e.g. I like George W. Bush: yes/no) to mem- 
ory retrieval (Zysset, Huber, Ferstl, \& von Cramon, 2002) and a previous study in which subjects made attractiveness judgments (Nakamura et al., 1998). Along similar lines, a recent study demonstrated activation in this area when decisions about which face was preferred for a dinner-date compared to arbitrary choices (Turk et al., 2004). Moreover, a large body of literature implicates this region in theory-of-mind judgments and "selfreferential" processing (e.g. Gallagher et al., 2000; Gallagher, Jack, Roepstorff, \& Frith, 2002; Goel, Grafman, Sadato, \& Hallett, 1995; Gusnard, Akbudak, Shulman, \& Raichle, 2001; Johnson et al., 2002; Kelley et al., 2002). We speculate that the process of making attractiveness judgments, even in this rather artificial task whilst viewing static stimuli, also invokes theoryof-mind mechanisms in ascertaining what the judged individual might be thinking of the judge.

Left amygdala also showed modulation by task with greater activity when subjects judged attractiveness than age. In other experiments using similar manipulations, we have been unsuccessful in finding task differences in amygdala (Winston et al., 2002, 2003) consistent with evidence that responses in this region are relatively automatic and independent of spatial attention (Bentley, Vuilleumier, Thiel, Driver, \& Dolan, 2003; Vuilleumier, Armony, Driver, \& Dolan, 2001) or awareness (Morris, Ohman, \& Dolan, 1998; Whalen et al., 1998; Williams, Morris, McGlone, Abbott, \& Mattingley, 2004). Other authors have found increases (Gorno-Tempini et al., 2001; Gur et al., 2002) or decreases (Hariri, Bookheimer, \& Mazziotta, 2000; Ochsner, Bunge, Gross, \& Gabrieli, 2002) in amygdala activity when an emotionally directed task is compared to a control task. It is presently unclear what differences between paradigms and tasks might explain these discrepant results and we are therefore cautious in interpreting this activation. However, it is noteworthy that this activation was selective to left amygdala, as demonstrated by the absence of an equivalent effect on the right and a significant hemisphere-by-condition interaction. This finding parallels the demonstration of Morris et al. (1998) that left amygdala activation was associated with observation of unmasked fear-conditioned faces, whereas right amygdala showed activation to masked presentations only. The current finding of left amygdala enhancement under direct task conditions is broadly consistent with that earlier demonstration of hemispheric asymmetry in amygdala function with left amygdala engaged by explicit processing.

The single region activated in the age judgment task (posterior cingulate/retrosplenial cortex) is a region consistently recruited in memory retrieval (Maguire, 2001a, 2001b) including retrieval of memory for faces (Shah et al., 2001). This suggests that subjects used memory-dependent strategies for the age task, perhaps comparing the stimuli to familiar faces or by recalling their response on a previous encounter with the identical face (stimuli were repeated twice in each task).

One disadvantage or our experimental design is the absence of a true baseline or a third task type against which age and attractiveness judgments could be compared. Without such an addition it is hard to comment on to what extent these two types of judgment from faces actually draw upon a shared network of regions. Our results must be interpreted as representing regions showing differences in levels of activity between these two tasks, rather than absolutely engaged by one and not by the other. Thus, STS (to take a likely example) might be activated in age judgments from faces, merely less so than during attractiveness judgments.

In conclusion, we have demonstrated that a number of brain regions are engaged when subjects judge facial attractiveness, and that these regions are largely dissociable from those that show relationships between perceived attractiveness and BOLD activation. With regard to the latter, a number, including rewardresponsive regions in medial prefrontal and orbitofrontal cortex, showed modulation by the task that subjects were performing. Along with our demonstration of non-linear response profiles in medial OFC this implies a complexity in the behaviour of these regions that has not previously been addressed by neurofunctional studies. Finally, the response profile of amygdala demonstrates a role for this region in encoding value (a nonlinear function of valence) from stimuli in the environment.

\section{Acknowledgements}

We thank the radiographers at the FIL for assistance with scanning. This work was supported by a Wellcome Trust Programme Grant to RJD.

\section{References}

Adolphs, R. (2003). Cognitive neuroscience of human social behaviour. Nature Reviews Neurosciences, 4(3), 165-178.

Aharon, I., Etcoff, N., Ariely, D., Chabris, C. F., O’Connor, E., \& Breiter, H. C. (2001). Beautiful faces have variable reward value: fMRI and behavioral evidence. Neuron, 32(3), 537-551.

Anderson, A. K., Christoff, K., Stappen, I., Panitz, D., Ghahremani, D. G., Glover, G., et al. (2003). Dissociated neural representations of intensity and valence in human olfaction. Nature Neuroscience, 6(2), 196-202.

Baxter, M. G., \& Murray, E. A. (2002). The amygdala and reward. Nature Reviews Neurosciences, 3(7), 563-573.

Bentley, P., Vuilleumier, P., Thiel, C. M., Driver, J., \& Dolan, R. J. (2003) Cholinergic enhancement modulates neural correlates of selective attention and emotional processing. Neuroimage, 20(1), 58-70.

Bonda, E., Petrides, M., Ostry, D., \& Evans, A. (1996). Specific involvement of human parietal systems and the amygdala in the perception of biological motion. Journal of Neuroscience, 16(11), 3737-3744.

Brunet, E., Sarfati, Y., Hardy-Bayle, M. C., \& Decety, J. (2000). A PET investigation of the attribution of intentions with a nonverbal task. Neuroimage, 11(2), 157-166.

Buchel, C., Holmes, A. P., Rees, G., \& Friston, K. J. (1998). Characterizing stimulus-response functions using nonlinear regressors in parametric fMRI experiments. Neuroimage, 8(2), 140-148.

Buchel, C., Josephs, O., Rees, G., Turner, R., Frith, C. D., \& Friston, K. J. (1998). The functional anatomy of attention to visual motion. A functional MRI study. Brain, 121(Pt 7), 1281-1294.

Castelli, F., Happe, F., Frith, U., \& Frith, C. (2000). Movement and mind: A functional imaging study of perception and interpretation of complex intentional movement patterns. Neuroimage, 12(3), 314-325.

Chen, N. K., Dickey, C. C., Yoo, S. S., Guttmann, C. R., \& Panych, L. P. (2003). Selection of voxel size and slice orientation for fMRI in the presence of susceptibility field gradients: Application to imaging of the amygdala. Neuroimage, 19(3), 817-825.

Corbetta, M., Miezin, F. M., Dobmeyer, S., Shulman, G. L., \& Petersen, S. E. (1991). Selective and divided attention during visual discriminations of shape, color, and speed: Functional anatomy by positron emission tomography. Journal of Neuroscience, 11(8), 2383-2402. 
Critchley, H., Daly, E., Phillips, M., Brammer, M., Bullmore, E., Williams, S., et al. (2000). Explicit and implicit neural mechanisms for processing of social information from facial expressions: A functional magnetic resonance imaging study. Human Brain Mapping, 9(2), 93-105.

Critchley, H. D. (2004). The human cortex responds to an interoceptive challenge. Proceedings of the National Academy of Sciences of the United States of America, 101(17), 6333-6334.

Critchley, H. D., Elliott, R., Mathias, C. J., \& Dolan, R. J. (2000). Neural activity relating to generation and representation of galvanic skin conductance responses: A functional magnetic resonance imaging study. Journal of Neuroscience, 20(8), 3033-3040.

Critchley, H. D., Mathias, C. J., Josephs, O., O’Doherty, J., Zanini, S., Dewar, B. K., et al. (2003). Human cingulate cortex and autonomic control: Converging neuroimaging and clinical evidence. Brain, 126(Pt 10), 2139-2152.

Deffenbacher, K. A., Vetter, T., Johanson, J., \& O’Toole, A. J. (1998). Facial aging, attractiveness, and distinctiveness. Perception, 27(10), 1233-1243.

Deichmann, R., Gottfried, J. A., Hutton, C., \& Turner, R. (2003). Optimized EPI for fMRI studies of the orbitofrontal cortex. Neuroimage, 19(2 Pt 1), $430-441$.

Dolan, R. J. (2002). Emotion, cognition, and behavior. Science, 298(5596), $1191-1194$.

Donaldson, D. I. (2004). Parsing brain activity with fMRI and mixed designs: What kind of a state is neuroimaging in? Trends in Neurosciences, 27(8), $442-444$.

Elliott, R., Newman, J. L., Longe, O. A., \& Deakin, J. F. (2003). Differential response patterns in the striatum and orbitofrontal cortex to financial reward in humans: A parametric functional magnetic resonance imaging study. Journal of Neuroscience, 23(1), 303-307.

Fink, B., \& Penton-Voak, I. (2002). Evolutionary psychology of facial attractiveness. Current Directions in Psychological Science, 11(5), 154158.

Frieze, I. H., 1son, J. E., \& Russell, J. (1991). Attractiveness and income for men and women in management. Journal of Applied Social Psychology, 21(13), 1039-1057.

Friston, K., Ashburner, J., Frith, C. D., Poline, J.-B., Heather, J. D., \& Frackowiak, R. S. J. (1995). Spatial registration and normalization of images. Human Brain Mapping, 2, 165-189.

Friston, K., Holmes, A. P., Worsley, K., Poline, J.-B., Frith, C., \& Frackowiak, R. S. J. (1995). Statistical parametric maps in functional imaging: A general linear approach. Human Brain Mapping, 2, 189-210.

Friston, K. J., Fletcher, P., Josephs, O., Holmes, A., Rugg, M. D., \& Turner, R. (1998). Event-related fMRI: Characterizing differential responses. Neuroimage, 7(1), 30-40.

Frith, C. D., \& Frith, U. (1999). Interacting minds-a biological basis. Science, 286(5445), 1692-1695.

Gallagher, H. L., Happe, F., Brunswick, N., Fletcher, P. C., Frith, U., \& Frith, C. D. (2000). Reading the mind in cartoons and stories: An fMRI study of 'theory of mind' in verbal and nonverbal tasks. Neuropsychologia, 38(1), $11-21$.

Gallagher, H. L., Jack, A. I., Roepstorff, A., \& Frith, C. D. (2002). Imaging the intentional stance in a competitive game. Neuroimage, $16(3 \mathrm{Pt} 1)$, 814-821.

Garavan, H., Pendergrass, J. C., Ross, T. J., Stein, E. A., \& Risinger, R. C. (2001). Amygdala response to both positively and negatively valenced stimuli. Neuroreport, 12(12), 2779-2783.

Glaser, D., \& Friston, K. J. (2003). Variance components. In R. S. J. Frackowiak, K. J. Friston, C. D. Frith, R. J. Dolan, C. J. Price, J. T. Ashburner, W. D. Penny, \& S. Zeki (Eds.), Human brain function (2nd ed.). Academic Press.

Goel, V., Grafman, J., Sadato, N., \& Hallett, M. (1995). Modeling other minds. Neuroreport, 6(13), 1741-1746.

Gorno-Tempini, M. L., Pradelli, S., Serafini, M., Pagnoni, G., Baraldi, P., Porro, C., et al. (2001). Explicit and incidental facial expression processing: An fMRI study. Neuroimage, 14(2), 465-473.

Gur, R. C., Schroeder, L., Turner, T., McGrath, C., Chan, R. M., Turetsky, B. I., et al. (2002). Brain activation during facial emotion processing. Neuroimage, 16(3 Pt 1), 651-662.
Gusnard, D. A., Akbudak, E., Shulman, G. L., \& Raichle, M. E. (2001). Medial prefrontal cortex and self-referential mental activity: Relation to a default mode of brain function. Proceedings of the National Academy of Sciences of the United States of America, 98(7), 4259-4264.

Hamann, S. B., Ely, T. D., Grafton, S. T., \& Kilts, C. D. (1999). Amygdala activity related to enhanced memory for pleasant and aversive stimuli. Nature Neuroscience, 2(3), 289-293.

Hamann, S. B., Ely, T. D., Hoffman, J. M., \& Kilts, C. D. (2002). Ecstasy and agony: Activation of the human amygdala in positive and negative emotion. Psychological Science, 13(2), 135-141.

Hariri, A. R., Bookheimer, S. Y., \& Mazziotta, J. C. (2000). Modulating emotional responses: Effects of a neocortical network on the limbic system. Neuroreport, 11(1), 43-48.

Hasselmo, M. E., Rolls, E. T., \& Baylis, G. C. (1989). The role of expression and identity in the face-selective responses of neurons in the temporal visual cortex of the monkey. Behavioural Brain Research, 32(3), 203-218.

Haxby, J. V., Hoffman, E. A., \& Gobbini, M. I. (2000). The distributed human neural system for face perception. Trends in Cognitive Sciences, 4(6), 223-233.

Henderson, J. A., \& Anglin, J. M. (2003). Facial attractiveness predicts longevity. Evolution and Human Behavior, 24(5), 351-356.

Henson, R. N., Buchel, C., Josephs, O., \& Friston, K. (1999). The slicetiming problem in event-related fMRI. Neuroimage, 9, 125.

Ishi, H., Jiro, G., Kamachi, M., Mukaida, S., \& Akamatsu, S. (2004). Analyses of facial attractiveness on feminised and juvenilised faces. Perception, 33(2), 135-145.

Johnson, S. C., Baxter, L. C., Wilder, L. S., Pipe, J. G., Heiserman, J. E., \& Prigatano, G. P. (2002). Neural correlates of self-reflection. Brain, 125(Pt 8), 1808-1814.

Josephs, O., \& Henson, R. N. (1999). Event-related functional magnetic resonance imaging: Modelling, inference and optimization. Philosophical Transactions of the Royal Society of London B: Biological Sciences, 354(1387), 1215-1228.

Kelley, W. M., Macrae, C. N., Wyland, C. L., Caglar, S., Inati, S., \& Heatherton, T. F. (2002). Finding the self? An event-related fMRI study. Journal of Cognitive Neuroscience, 14(5), 785-794.

Maguire, E. A. (2001a). Neuroimaging studies of autobiographical event memory. Philosophical Transactions of the Royal Society of London Series B: Biological Sciences, 356(1413), 1441-1451.

Maguire, E. A. (2001b). The retrosplenial contribution to human navigation: A review of lesion and neuroimaging findings. Scandanavian Journal of Psychology, 42(3), 225-238.

Morris, J. S., Ohman, A., \& Dolan, R. J. (1998). Conscious and unconscious emotional learning in the human amygdala. Nature, 393(6684), 467470 .

Nakamura, K., Kawashima, R., Nagumo, S., Ito, K., Sugiura, M., Kato, T., et al. (1998). Neuroanatomical correlates of the assessment of facial attractiveness. Neuroreport, 9(4), 753-757.

Narumoto, J., Okada, T., Sadato, N., Fukui, K., \& Yonekura, Y. (2001). Attention to emotion modulates fMRI activity in human right superior temporal sulcus. Brain Research: Cognitive Brain Research, 12(2), 225-231.

O'Doherty, J., Winston, J., Critchley, H., Perrett, D., Burt, D. M., \& Dolan, R. J. (2003). Beauty in a smile: The role of medial orbitofrontal cortex in facial attractiveness. Neuropsychologia, 41(2), 147-155.

O'Toole, A. J., Deffenbacher, K. A., Valentin, D., McKee, K., Huff, D., \& Abdi, H. (1998). The perception of face gender: The role of stimulus structure in recognition and classification. Memory and Cognition, 26(1), $146-160$.

Ochsner, K. N., Bunge, S. A., Gross, J. J., \& Gabrieli, J. D. (2002). Rethinking feelings: An FMRI study of the cognitive regulation of emotion. Journal of Cognitive Neuroscience, 14(8), 1215-1229.

Pashos, A., \& Niemitz, C. (2003). Results of an explorative empirical study on human mating in Germany: Handsome men, not high-status men, succeed in courtship. Anthropologischer Anzeiger, 61(3), 331341 .

Perrett, D. I., Lee, K. J., Penton-Voak, I., Rowland, D., Yoshikawa, S., Burt, D. M., et al. (1998). Effects of sexual dimorphism on facial attractiveness. Nature, 394(6696), 884-887. 
Puce, A., Allison, T., Bentin, S., Gore, J. C., \& McCarthy, G. (1998). Temporal cortex activation in humans viewing eye and mouth movements. Journal of Neuroscience, 18(6), 2188-2199.

Robinson, S., Windischberger, C., Rauscher, A., \& Moser, E. (2004). Optimized 3 T EPI of the amygdalae. Neuroimage, 22(1), 203-210.

Sander, D., Grafman, J., \& Zalla, T. (2003). The human amygdala: An evolved system for relevance detection. Reviews in the Neurosciences, 14(4), 303-316.

Shah, N. J., Marshall, J. C., Zafiris, O., Schwab, A., Zilles, K., Markowitsch, H. J., et al. (2001). The neural correlates of person familiarity. A functional magnetic resonance imaging study with clinical implications. Brain, 124(Pt 4), 804-815.

Singer, T., Kiebel, S. J., Winston, J. S., Dolan, R. J., \& Frith, C. D. (2004). Brain responses to the acquired moral status of faces. Neuron, 41(4), 653-662.

Small, D. M., Gregory, M. D., Mak, Y. E., Gitelman, D., Mesulam, M. M., \& Parrish, T. (2003). Dissociation of neural representation of intensity and affective valuation in human gustation. Neuron, 39(4), 701711.

Teves, D., Videen, T. O., Cryer, P. E., \& Powers, W. J. (2004). Activation of human medial prefrontal cortex during autonomic responses to hypoglycemia. Proceedings of the National Academy of Sciences of the United States of America, 101(16), 6217-6221.

Thornhill, R., \& Gangestad, S. W. (1999). Facial attractiveness. Trends in Cognitive Sciences, 3(12), 452-460.

Thornhill, R., Gangestad, S. W., \& Comer, R. (1995). Human female orgasm and mate fluctuating asymmetry. Animal Behaviour, 50, 1601-1615.

Turk, D. J., Banfield, J. F., Walling, B. R., Heatherton, T. F., Grafton, S. T., Handy, T. C., et al. (2004). From facial cue to dinner for two: The neural substrates of personal choice. Neuroimage, 22(3), 1281-1290.
Vuilleumier, P., Armony, J. L., Driver, J., \& Dolan, R. J. (2001). Effects of attention and emotion on face processing in the human brain: An event-related fMRI study. Neuron, 30(3), 829-841.

Whalen, P. J., Rauch, S. L., Etcoff, N. L., McInerney, S. C., Lee, M. B., \& Jenike, M. A. (1998). Masked presentations of emotional facial expressions modulate amygdala activity without explicit knowledge. Journal of Neuroscience, 18(1), 411-418.

Williams, M. A., Morris, A. P., McGlone, F., Abbott, D. F., \& Mattingley, J. B. (2004). Amygdala responses to fearful and happy facial expressions under conditions of binocular suppression. Journal of Neuroscience, 24(12), 2898-2904.

Wilson, M., \& Daly, M. (2004). Do pretty women inspire men to discount the future? Biology Letters, 271(S4), 177-179.

Winston, J. S., Henson, R. N., Fine-Goulden, M. R., \& Dolan, R. J. (2004), fMRI-adaptation reveals dissociable neural representations of identity and expression in face perception. Journal of Neurophysiology, 92(3), 1830-1839.

Winston, J. S., O'Doherty, J., \& Dolan, R. J. (2003). Common and distinct neural responses during direct and incidental processing of multiple facial emotions. Neuroimage, 20(1), 84-97.

Winston, J. S., Strange, B. A., O'Doherty, J., \& Dolan, R. J. (2002). Automatic and intentional brain responses during evaluation of trustworthiness of faces. Nature Neuroscience, 5(3), 277-283.

Worsley, K., Marrett, S., Neelin, P., Vandal, A. C., Friston, K. J., \& Evans, A. C. (1996). A unified statistical approach for determining significant signals in images of cerebral activation. Human Brain Mapping, 4(1), $58-73$.

Zysset, S., Huber, O., Ferstl, E., \& von Cramon, D. Y. (2002). The anterior frontomedian cortex and evaluative judgment: An fMRI study. Neuroimage, 15(4), 983-991. 